\title{
Investigation of using bleaching earth and activated carbon mixturein sunfloweroilrefining
}

\author{
Ibrahimov Hikmet Jamal., Guliyev Nihad Gudret., Alekperov Jamil Arif., Amirov Fariz Ali., Ibrahimova Zenfira \\ Meherrem \\ Institute of Petrochemical Processes named after Academician Yu.H.Mamedaliyev, \\ Baku, Azerbaijan. \\ E-mail: nihad.quliyev@azersun.com \\ ibragimov-khikmet@rambler.ru
}

\begin{abstract}
Adsorption is one commonly used technique for treatment of sunflower oil. In this study, activated carbon and bleaching earth as a bleaching agent mixed with certain proportions and $1 \%$ of the mixture added to sunflower oil in the bleaching process. The combination of bleaching earth and activated carbon produced higher adsorption capacity than the single bleaching earth. This article focuses more particularly on heavy metals and polycyclic aromatic hydrocarbons (PAHs) removal. It was detected that, the mixture is an excellent adsorbent in the adsorption of PAHs and metals from sunflower oil with the highest adsorption capacity. The results showed that, the adsorption of metals and PAHs depend strongly on activated carbon and decreased with increasing activated carbonin mixture and the maximum adsorption was reached after using B5 (95\% bleaching earth and $5 \%$ activated carbon combination).
\end{abstract}

Keywords: sunflower oil, bleaching, bleaching earth, activated carbon, polycyclic aromatic hydrocarbons (PAHs)

\section{INTRODUCTION}

Most vegetable oils are obtained from the seeds and fruits of plants. Vegetable oils are eaten directly and also used in the production of margarines, frying oils and other edible products in food industry. Besides the food industry, they also have applications in leather, paint, rubber, oleo-chemical, textile and pharmaceutical industries. Sunflower oilis composed mainly of triacylglyceroland a small amount of monoacylglycerols, diacylglycerols, phospholipids, tocopherols, sterols, peroxides, metals, free fatty acids, carotenoids, chlorophylls and waxes and so on. Carotenoids and chlorophylls give sunflower oil light-amber color, turning to pale yellow upon the bleaching process [1].

It is important to have proper refining process in order to produce high quality finished product with specified quality range that meet user's requirements. The aim ofrefining process is to remove colored particles, phosphatides, tracemetals, and free fatty acids which may produce oxidation products leading to decomposition [2]. There are basically two types of refining processes available in the vegetable oils industries, namely, chemical and physical refining $[3,4]$. Chemical refining involves degumming, neutralization, bleaching, dewaxing, and deodorization process. Among these stages, bleaching is the most critical process; it helps to improve the flavor, taste, appearance and stability of the vegetable oil [5]. Bleaching stage is designed to remove not only pigments, but also other impurities such as soaps, phosphatides and free fatty acids. The main method of bleaching is adsorption of the coloring substances on adsorbents. In vegetable oil industry, factories usually use acid activated bleaching earth (bentonite), natural bleaching earth, activated carbon and synthetic silicates [6,7].

During the bleaching process, the oil is brought into contact with bleaching substances that adsorb undesired particles. Then,the adsorbent and the adsorbate are filtered off, and the oil leaves the process with the desired color. However, bleaching agents may play as a catalyst for oxidation in the participation of oxygen at high temperatures. These oxidation products lead to degradationof triacylglyceroland final productshelf life is reduced.Therefore the bleaching process is carried out under vacuum. Oxidationproducts should also be removed during bleaching to provide suitable shelf life oil. Lastly, some heavy metals should also be removed in this stage $[8,9]$.Color is an important indicator of bleaching effectiveness, soaps, phosphorus, peroxide, and anisidine values are also some key quality indicators associated with the bleaching process.Furthermore, for an efficient bleaching process you must remove some contaminants before bleaching in the refining process. For example, phosphorus $(\mathrm{P})$ after degumming and neutralization processes should be reduced to $10 \mathrm{mg} / \mathrm{kg}$, free fatty acids (FFA)to $0.1 \%$ and soaps to $50 \mathrm{mg} / \mathrm{kg}[10,11]$.

Adsorption is the separation process with the help of special adsorbents. There is a variety of adsorbents. The most wellknownare bleaching earth (BE), activated carbon (AC), synthetic silicates, and synthetic resins in vegetable oil industry.AC is an efficient adsorbent, which has a largeinternal surface area and large pore volume. Good porous texture gives activated carbon very high adsorption capacity in the removal of organic compounds such as PAHs, chlorophyll from vegetable oil.It is known that the treatment of oils and fats with certain activated carbons leads to an effective removal especially of the 'heavy' PAHs. The activated carbons can be used alone or together with the bleaching earth to adsorb PAHs. Activated carbons available commercially are produced from various base materials and have consequently different adsorption capacity for PAHs. Some manufacturers offer activated carbons with a standardized efficiency. The removal of the heavy PAHs is done by means of activated carbons. But light PAHs removed from oil in deodorization. Therefore activated carbon treatment and deodorization complement each other ideally to obtain fats and oils free of $\mathrm{PAH}[12-14]$.

Heavy metals such as cadmium, arsenicand mercury enter to vegetable oil from environment. Copperand ironare found in the vegetable oil naturally; they can also enter the oil from iron and copper-containing equipment during processing. Codex Alimentarius and the European Commissionhave been determined limit values of these metals in vegetable oil[1516]. 
Removal of metals and PAHs using of $\mathrm{AC}$ and bleaching earth combination was investigated in this work, and it was found that the ratio of $5: 95$ activated carbon and bleaching earth combinations are more effective in the treatment of sunflower oil than single bleaching earth.

\section{MATERIALS AND METHODS}

\subsection{Materials}

Activated carbon sample $\mathrm{A} 1$ obtained from $\mathrm{C}_{5}$ fraction pyrolysis in the presence of a ferrocene catalyst and on the surface of $\mathrm{Al}_{2} \mathrm{O}_{3}$ in $920^{\circ} \mathrm{C}$, during 20 minute and Argon atmosphere in CVD unit. Then chemical agents (Mg, Al and other ions) are removed by washing with sulfuric acid, which leaves a highly porous structure and then dried under vacuum. A bleaching earth sample A2 was supplied from a commercial company. After that, bleaching earth and activated carbon are mixed certain proportions and then $1 \%$ mix is added to sunflower oil bleaching process. The crudeand neutralized sunflower oil (SF) was obtained from Baku Oil Factory in Azerbaijan Republic. All reagents, solvents and standard stock solutions used were from Merck.

\subsection{Methods}

The bleaching of sunflower oil was carried out according to AOCS Cc 8f-91. Initially, 100 gram of sunflower oil was poured into a $500 \mathrm{ml}$ Erlenmeyer flask. Bleaching earth and activated carbon are mixed certain proportions which shown below:B1 - $1 \%$ activated carbon and $99 \%$ bleaching earth mixture; B2 - $2 \%$ activated carbon and $98 \%$ bleaching earth mixture; B3 - $3 \%$ activated carbon and $97 \%$ bleaching earth mixture; B4 - $4 \%$ activated carbon and $96 \%$ bleaching earth mixture; B5 - $5 \%$ activated carbon and $95 \%$ bleaching earth mixture. Then 1 gram of sample B1 was added to the 100 gram sunflower oil and mixed. The temperature was maintained at $40^{\circ} \mathrm{C}$ for 30 minutes. Then, the mixture was filtered through Whatman No 4 filter paper. This process was repeated with B2, B3, B4 and B5 samples in order to determine the effect of increase in activated carbon proportion. The effect of temperature was studied at $60,70,80,90$ and $100^{\circ} \mathrm{C}[17]$.

\subsection{Analysis of oil}

\section{Trace metals}

The metal analysis was made on Perkin Elmer Nexion 300 ICP-MS.Approximately 1 gram samples were weighed and digested with $9 \mathrm{~mL} \mathrm{HNO}_{3}$ and $1 \mathrm{ml} \mathrm{H}_{2} \mathrm{O}_{2}$ in microwave digestion system. After complete digestion and removal of acid, the samples were adjusted to $5 \mathrm{~mL}$ with ultrapure water, and ready for measurement.Also, one blank sample was subjected to same procedure. Appropriate quality assurance and quality control procedures were followed to ensure the reliability of obtained data[18]. The experiments were performed in duplicate.

\section{Polycyclic aromatic hydrocarbons (PAHs)}

The removalprocesses of PAHs from sunflower oil with activated carbon have been revised in this article. The PAHs wereanalyzed by on-line coupling of donor-acceptor complex chromatography (DACC) and HPLC with fluorescence detection according to ISO 22959in vegetable oils. PAHs which can be determined by this method are:anthracene, phenanthrene, fluoranthene, pyrene, chrysene, benzo[a]anthracene, benzo[e]pyrene, benzo[a]pyrene, perylene, benzo[ghi]perylene, anthanthrene, dibenzo[a,h]anthracene, coronene, indeno[1,2,3-cd]pyrene,benzo[a]fluoranthene, benzo[b]fluoranthene, benzo[k]fluoranthene $[19,20]$.Calibration was performed using standard PAH mixtures at seven different concentrations: $0.5,1,2,5,10,20$, and $50 \mu \mathrm{g} / \mathrm{L}$ (conversion to the samples of 2, 4, 8, 20, 40 and $200 \mu \mathrm{g} / \mathrm{kg}$ )for all 17 PAHs. The linearity of the calibrationcurves was assessed by the peak area. Good linearity was observed in the concentration range studied with correlationcoefficients $>0.999$.

\section{RESULTS AND DISCUSSION}

Adsorption has been widely studied as an effective technique for removing organic contaminants and metalsfrom vegetable oil. The removal efficiency is influenced by various factors such as adsorbent types, bleaching time,adsorbent dosage and temperature and so on. In this study, metal andPAH content were determined to see oil quality before and after bleaching process.

\subsection{Adsorption of PAHs}

PAHscontaminated vegetable oils pose a threat to human health and ecology.During the refining process all PAHs should be eliminated. Heavy PAHs are eliminated by the deodorization step, whereas light ones are eliminated when treated with activated carbon during the bleaching step. The one of main proposes of this work was to adsorb this pollutants from sunflower oil using activated carbon mixed samples[21].

In order to establish the concentration for maximum adsorption of PAHs from sunflower oil, bleaching earth and activated carbon mixed. The study was carried out with $1 \mathrm{gram}$ adsorbent in $100 \mathrm{ml}$ sunflower oil. The changes in the amount of $\mathrm{PAH}$ s depending on the adsorbents are reported in the Table 1. The bleaching using bleaching earth sample (A2) shows that there was no significant change in the removal of PAHs. However, the maximum PAH removal was achieved at using activated carbon (A1). When comparing B1 and B5 mixtures, PAH removal increased with increasing activated carbon in the mixture. The lowest adsorption capacity was achieved at using B1 and it slightly increase with increasing the activated carbon in mixture. Both B4 and B5 showed similar behavior at PAH removal, although benzo (b) fluoranthene removal with 
B5 is considerably higher than B4. It is clear that, activated carbon adsorbed especially heavy PAHs. The heavy PAHs removal was significantly higher than light PAHs removal using B5.

The chromatograms of a standart PAH mixture (1) and crude sunflower oil (2) are shown in Figure 1. It is clear that, 15 PAHs found in crude sunflower oil and their quantity are $11.05 \mu \mathrm{g} / \mathrm{kg}$ and benzo(b) fluoranthene is the highest PAH (1.18 $\mu \mathrm{g} / \mathrm{kg}$ ) in the sunflower oil.

Moreover, temperature impact on PAHs removal was investigated and it was determined that increase of temperature does not impact to removal PAHs. Bleaching in $100{ }^{\circ} \mathrm{C}$ temperature is not differ compared to $40{ }^{\circ} \mathrm{C}$ in PAH removal, but color removal in $100^{\circ} \mathrm{C}$ is more than $40^{\circ} \mathrm{C}$ due to bleaching earth comparing B1 and B5.

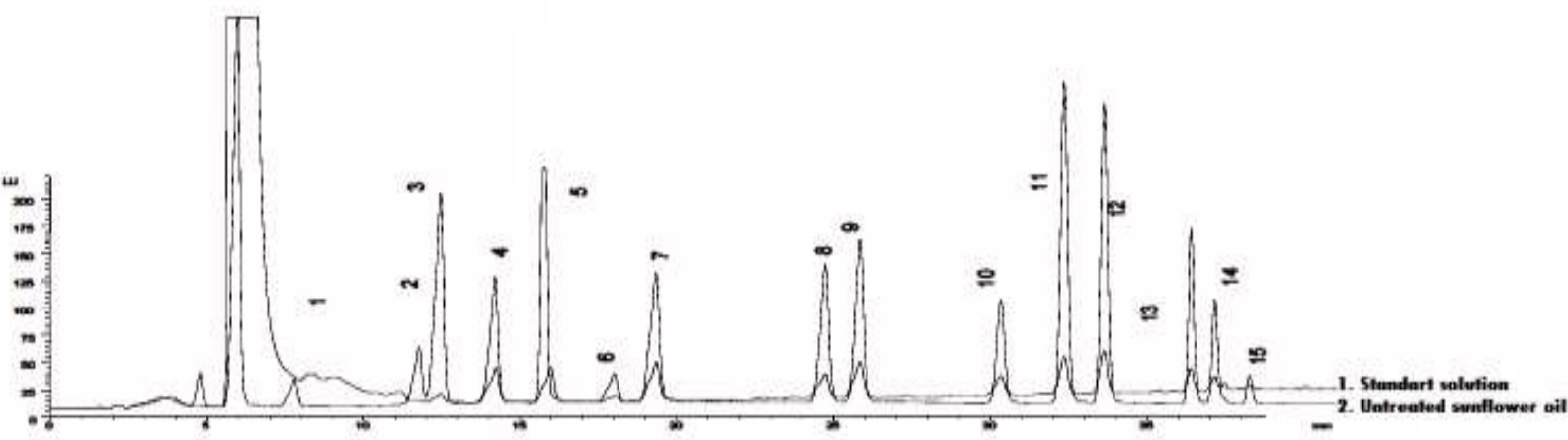

Figure 1.Chromatograms of standard solution (1) and crude sunflower oil (2).

Table 1.The analysis results of the polyaromatic hydrocarbon contamination (PAH) of sunflower oil samples before and after bleaching.

\begin{tabular}{|c|c|c|c|c|c|c|c|c|c|}
\hline $\begin{array}{l}\text { Adserbents } \\
\text { PAHs }\end{array}$ & Sunflower oil & $\begin{array}{l}\text { Expanded } \\
\text { uncertainty }\end{array}$ & A1 & A2 & B1 & B2 & B3 & B4 & B5 \\
\hline Naphtalene & 0.62 & 0.082 & 0.63 & 0.61 & 0.61 & 0.62 & 0.63 & 0.61 & 0.61 \\
\hline Acenaphthylene & 0.55 & 0.059 & 0.56 & 0.55 & 0.54 & 0.57 & 0.56 & 0.54 & 0.56 \\
\hline Acenapthene & 0.72 & 0.073 & 0.71 & 0.72 & 0.72 & 0.73 & 0.71 & 0.72 & 0.71 \\
\hline Fluorene & 0.79 & 0.077 & 0.78 & 0.79 & 0.79 & 0.8 & 0.78 & 0.79 & 0.78 \\
\hline Phenanthrene & 0.72 & 0.106 & 0.71 & 0.72 & 0.72 & 0.71 & 0.73 & 0.71 & 0.72 \\
\hline Anthracene & 0.56 & 0.054 & 0.56 & 0.57 & 0.57 & 0.56 & 0.55 & 0.57 & 0.56 \\
\hline Fluoranthene & 0.79 & 0.039 & 0.8 & 0.79 & 0.8 & 0.78 & 0.79 & 0.79 & 0.8 \\
\hline Pyrene & 0.84 & 0.068 & 0.83 & 0.83 & 0.84 & 0.82 & 0.83 & 0.84 & 0.83 \\
\hline Benzo (a) anthracene & 0.78 & 0.079 & 0.78 & 0.79 & 0.78 & 0.79 & 0.77 & 0.78 & 0.78 \\
\hline Chrysene & 0.83 & 0.09 & 0.82 & 0.82 & 0.82 & 0.83 & 0.81 & 0.82 & 0.81 \\
\hline $\begin{array}{c}\text { Total light } \\
\text { PAHclwa/kal }\end{array}$ & 7.2 & & 7.18 & 7.19 & 7.19 & 7.21 & 7.16 & 7.17 & 7.16 \\
\hline Benzo(b) fluoranthene & 1.18 & 0.048 & $<0.5$ & 1.18 & 0.97 & 0.89 & 0.76 & 0.55 & $<0.5$ \\
\hline Benzo(k) fluoranthene & 1.1 & 0.061 & $<0.5$ & 1.11 & 0.93 & 0.67 & 0.52 & $<0.5$ & $<0.5$ \\
\hline Benzo(a) pyrene & 0.58 & 0.043 & $<0.5$ & 0.59 & 0.51 & $<0.5$ & $<0.5$ & $<0.5$ & $<0.5$ \\
\hline Dibenzo (ah) & 0.53 & 0.057 & $<0.5$ & 0.51 & $<0.5$ & $<0.5$ & $<0.5$ & $<0.5$ & $<0.5$ \\
\hline Benzo(ghi) perylene & 0.64 & 0.118 & $<0.5$ & 0.63 & 0.6 & 0.51 & $<0.5$ & $<0.5$ & $<0.5$ \\
\hline $\begin{array}{l}\text { Total heavy } \\
\text { PAHc(ug/kg) }\end{array}$ & 4.03 & & $<0.5$ & 4.02 & 3.01 & 2.07 & 1.28 & 0.55 & $<0.5$ \\
\hline TOTAL PAHs $(\mu \mathrm{g} / \mathrm{kg})$ & 11.05 & & 7.18 & 11.21 & 10.2 & 9.28 & 8.44 & 7.72 & 7.16 \\
\hline
\end{tabular}

Value showed in the Table 1 should be multiplied by the expanded uncertainty for corresponding concentration in order to receive the result with uncertainty. Results are given in the following form:

Results $=$ Value obtained \pm Expanded uncertainty $x$ Value obtained 


\subsection{Adsorption of trace metals}

The determination of trace metals in vegetable oils is an important criterion for the assessment of oil quality.The adsorption of some metals from sunflower oil onto activated carbon and bleaching earth mixture was investigated under bleaching conditions, $100{ }^{\circ} \mathrm{C}$ temperature and 30 minutes contact time. The results were obtained as the average of two replicates of each sample and are shown in Table 2. The results showed that the untreated sunflower oil contained many elements ( $\mathrm{Fe}, \mathrm{Pb}, \mathrm{As}, \mathrm{Hg}, \mathrm{Ni}, \mathrm{Cd}, \mathrm{Cu}, \mathrm{Sn}$ and $\mathrm{Zn}$ ) which are useful or harmful to human health, and the concentrations ranged from 1.4 to $38.1 \mu \mathrm{g} / \mathrm{kg}[21,22]$.

The adsorption effect of metals for both bleaching earth and activated carbon, and their mixtures were illustrated in Table 2. As shown, the metals adsorption capacity using activated carbon (A1) is higher than bleaching earth (A2). The highest metal adsorption capacity was achieved at using B5 and the lowest adsorption capacity was achieved at using B1. B5 remove metals more than B1 due to the amount of activated carbon. Generally, the highest result is shown B4 and B5, the result of 7 metals are negative bleaching with B5. It can be concluded that activated carbon (A1)is more appropriate adsorbents for the removal of metals from sunflower oil.Moreover, the results showed that the concentrations of heavy metals in bleached sunflower oil sample was low, all of which met the national hygiene standards and the dietary intakes of the selected heavy metals pose no significant health risk to population.

Table 2.The analysis results of the metals of the crude and bleached sunflower oil samples.

\begin{tabular}{|c|c|c|c|c|c|c|c|c|}
\hline $\begin{array}{l}\text { Metals, } \\
\mu \mathrm{g} / \mathrm{kg}\end{array}$ & $\begin{array}{c}\text { Crude } \\
\text { sunflower oil }\end{array}$ & A1 & $\mathrm{A} 2$ & B1 & B2 & B3 & B4 & B5 \\
\hline As & $11.2 \pm 0.61$ & $<0.5$ & $11.1 \pm 0.61$ & $9.94 \pm 0.54$ & $6.54 \pm 0.36$ & $3.49 \pm 0.19$ & $1.07 \pm 0.06$ & $<0.5$ \\
\hline $\mathrm{Hg}$ & $5.4 \pm 0.34$ & $<0.5$ & $3.63 \pm 0.23$ & $1.87 \pm 0.12$ & $0.66 \pm 0.04$ & $<0.5$ & $<0.5$ & $<0.5$ \\
\hline $\mathrm{Ni}$ & $16.8 \pm 1.38$ & $0.62 \pm 0.05$ & $15.44 \pm 1.27$ & $12.62 \pm 1.04$ & $9.07 \pm 0.75$ & $4.2 \pm 0.35$ & $2.17 \pm 0.18$ & $1.74 \pm 0.14$ \\
\hline $\mathrm{Cd}$ & $8.3 \pm 0.48$ & $<0.5$ & $3.7 \pm 0.22$ & $2.8 \pm 0.18$ & $1.05 \pm 0.06$ & $0.62 \pm 0.04$ & $<0.5$ & $<0.5$ \\
\hline Sn & $1.4 \pm 0.11$ & $<0.5$ & $0.92 \pm 0.07$ & $0.8 \pm 0.06$ & $0.64 \pm 0.05$ & $<0.5$ & $<0.5$ & $<0.5$ \\
\hline $\mathrm{Zn}$ & $51.1 \pm 3.28$ & $<0.5$ & $51.11 \pm 3.28$ & $30.95 \pm 2$ & $18.84 \pm 1.21$ & $6.62 \pm 0.42$ & $1.54 \pm 0.1$ & $<0.5$ \\
\hline
\end{tabular}

\section{CONCLUSION}

The analysis results show that the studied adsorbents can effectively adsorbed PAHs and heavy metals from sunflower oil. The lowest adsorption capacity was found using B1 (1\% activated carbon and $99 \%$ bleaching earth mixture) and the highest adsorption capacity was found using B5 (5\% activated carbon and $95 \%$ bleaching earth mixture). Both B4 (4\% activated carbon and $96 \%$ bleaching earth mixture) and B5 showed very familiar behavior at PAH removal, but B5 results are higher than B4. Moreover, B5 metal adsorption capacity was very high than B4. Also, it was determined that, temperature does not impact on PAH removal. It can be concluded that, the combination of activated carbon and bleaching earth is a good method to enhance the capacity of bleaching earth to adsorb contaminants, and $5 \%$ activated carbon and95\% bleaching earth combination(B5) exhibited a highest adsorption capacity and can be considered as the best adsorbent for the removal of PAHs and metals from vegetable oil.

\section{REFERENCES}

1.Gunstone, F.D., (2002), Vegetable oils in food technology: Composition, properties and uses, Backwell Publishing, 3-14.

2.R. E. Wainwright, in Y. H. Hui, ed., Bailey's Industrial Oil and Fat Products 5th ed., Vol. 3, Wiley, New York, 1996, pp. 353-408.

3. Physical and Chemical Characteristics of Oils, Fats and Waxes, in Official Methods and Recommended Practices of the American Oil Chemists' Society, AOCS Press, Champaign, Illinois, 1997. 
4.T. Wang, in F. D, Gunstone, ed., Vegetable Oils in Food Technology, Blackwell Publishing, Oxford, U.K., 2002, pp. 1858.

5. M. K. Gupta, in F. D. Gunstone, ed., Vegetable Oils in Food Technology, Blackwell Publishing, Oxford, U.K., 2002, pp. 128-156.

6.Rohani B. M. Z., Madia N.A.M. and Madya M. K.A, (2006), Process design in degumming and bleaching of Palm oil. UniversityTechnology Malaysia

7. P. Transfeld: Counter current system cuts bleaching cost. INFORM 7 (1996) 756.

8.Amuda, O. S.; Giwa, A. A. and Bello, I. A.: Removal of heavy metal from industrial wastewater using modified activated coconut shell carbon. Biochem. Eng. J., 2007, 36, 174-181

9. Berbesi R., (2006), Achieving Optimal Bleaching Performance, Oil Mill Gazetteer, 112,2-6.

10. B. Ostrich'-Matijasevic', J. Turkulov, And D. Karlovic': Quality of Sunflower Oil Bleached during Deodorization. J. Am. Oil Chem. Soc. 57(1980) 323.

11. Gemeinschaftsarbeiten der DGF, 117. Mitteilung: Dämpfung von Speisefetten und -ölen zur Desodorierung und Entsäuerung VII. Fat Sci. Technol. 92(1990) 459-463.

12. Ademiluyi, F. T.; Amadi, S. A. and Amakama, N. J.: Adsorption and treatment of organic contaminants using activated carbon from waste Nigerian Bamboo. J. Appl. Sci. Environ. Manage, 2009, 13 (3), 39 - 47.

13. Bansal R.C. \& Goyal M. (2005) "Activated Carbon Adsorption”, Taylor \& Francis, Boca Raton.

14. G. Biernoth, H. E. Rost: The Occurrence of Polycyclic Aromatic Hydrocarbons in Coconut Oil and their Removal. Chem. \& Ind. 1967, 2002; Vorkommen polycyclischer aromatischer Kohlenwasserstoffe in Speiseölen und deren Entfernung. Arch. Hyg. 152/3(1968) 238-250.

15. Ahn, C. K.; Kim, Y. M.; Woo, S. H. and Park, J. M.: Removal of cadmium using acid-treated activated carbon in the presence of nonionic and/or anionic surfactants. Hydrometallurgy, 2009, 99, 209-213.

16. Chen, J. P. and Wu, S.: Acid/base-treated activated carbons: characterization of functional groups and metal adsorptive properties. Langmuir, 2004, 20, 2233-2242.

17.AOCS Official Method Cc 8f-91. Official and Tentative Methods of the Am. Oil Chem. Soc., Champaign, IL (USA).

18. Sahan, Y., Basoglu, F., \& Gucer, S. (2007). ICP-MS analysis of a series of metals (Namely: Mg, Cr, Co, Ni, Fe, Cu, $\mathrm{Zn}, \mathrm{Sn}, \mathrm{Cd}$ and $\mathrm{Pb}$ ) in black and green olive samples from Bursa, Turkey. Food Chemistry, 105, 395-399.

19. ISO 22959:2009 (2012). Animal and vegetable fats and oils -Determination of polycyclic aromatic hydrocarbons by online donor-acceptor complex chromatography and HPLC with fluorescence detection.

20. van Stijn, F.; Kerkhoff, M. A.; Vandeginste, B. G. Determination of Polycyclic Aromatic Hydrocarbons in Edible Oils and fats by On-Line Donor-Acceptor Complex Chromatography and High-Performance Liquid Chromatography with Fluorescence Detection.J. Chromatogr., A1996, 750, 263-273.

21. Cejpek, K., Hajslova, J., Kocourek, V., Tomaniova, M., Cmolik, J., 1998. Changes in PAH levels during production of rapeseed oil.Food Addit.Contam. 15, 563-574.

21.European Commission, 2006. Commission Regulation (EC) No. 1881/2006 setting maximum levels of certain contaminants in foodstuffs. Off. J. Eur. Union L364/5-24.

22.European Commission, 2002. Opinion of the Scientific Committee on Food on the risks tohuman health of Polycyclic Aromatic hydrocarbons in food. 